\title{
Educating Technophile Artists and Artophile Technologists: A successful experiment in Higher Education
}

\author{
P.Comninos $^{\mathrm{a}}$, L.McLoughlin ${ }^{\mathrm{a}}$, E.F.Anderson ${ }^{\mathrm{b}}$ \\ ${ }^{a}$ The National Centre for Computer Animation, Media School, Bournemouth University, \\ Fern Barrow, Poole BH12 5BB, United Kingdom \\ ${ }^{b}$ Interactive Worlds ARG, Faculty for Engineering and Computing, Coventry University, \\ Priory Street, Coventry CV1 5FB, United Kingdom
}

\begin{abstract}
Over the past few decades, the arts have become increasingly dependent on and influenced by the development of computer technology. In the 1960s pioneering artists experimented with the emergent computer technology and more recently the majority of artists have come to use this technology to develop and even to implement their artefacts.

The traditional divide between art and technology - if it ever existed has been breaking down to the extent that a large number of artists consider themselves to be technophiles. In truth this divide has never existed. Throughout history artists have always used and exploited whatever technology existed and frequently led the development of new technology that would allow them to express their creativity. For instance the ancient Greek word for art was "Té $\nu \eta "$ " (technê) - the etymological root for the word "technology".

The divide between the arts and sciences, which we consider to be artificial and harmful, was only introduced in the western educational system in the 19th century and we believe that it is high time that it was bridged or removed altogether. To this end our centre has pioneered a number of university degrees that aim to blur the difference between artists and scientists / technologists.
\end{abstract}

Email addresses: peterc@bournemouth.ac.uk (P.Comninos), lmcloughlin@bournemouth.ac.uk (L.McLoughlin), eikea@siggraph.org (E.F.Anderson) 
In this paper we explore the design of such courses, taking into account the evolution of the field and the historical development of our centre, and we share with our audience our experiences, successes, and trials and tribulations in implementing such degrees in the area of computer animation, games and digital effects. We present a discussion of the syllabus employed in our highly successful undergraduate degree programme, giving examples of various assignment and assessment forms. Further, we discuss the common issues in educating technophile artists that we have identified on our undergraduate programme and the implications on the students' learning experience arising from these.

Keywords: Computer Animation Education, Digital Effects Education, Computer Games Education

\section{Introduction}

For the past twenty one years, the National Centre for Computer Animation (NCCA) has been at the forefront of computer graphics and computer animation education and research in the UK. Founded in 1989, our centre's aim is to educate individuals in the areas of Computer Animation, Digital Effects and Computer Games and our graduates are well sought after by these three industries, finding employment both nationally and internationally. Almost half of our graduates are employed by leading effects, animation and games production companies in the US, New Zealand and Australia. Our artworks are shown and exhibited internationally and have appeared frequently at the SIGGRAPH Electronic Theatre, Animation Theatres and Art Exhibition.

Over the past nineteen years we have conducted an experiment which has involved the design, development and implementation of a Computer Animation undergraduate programme. This programme is fundamentally different from other contemporary programmes and even by today's standards is unorthodox and differs from most other undergraduate programmes in this discipline. The success of this experiment can be judged in terms of its academic rigor, which has been praised by our external examiners, and its relevance to our industry, which is evidenced by the employability of its graduates.

Our motivation in writing this paper is to share our experiences and the knowledge that we have gained from this experiment, in developing and 
running such a programme, with our colleagues in the computer animation education field.

The philosophy, structure and curriculum content of this programme represents a radical departure from the perceived wisdom in the design of computer animation programmes, as it is neither an appendage to a Computer Science programme nor an Art or Traditional Animation programme. This experiment should thus neither be judged in Computer Science terms nor in Art terms alone, but rather in terms of the new discipline of Computer Animation.

For the reader to best appreciate and to fairly judge this experiment we first introduce the historical context in which it took place. In section 2, we present a brief history of the development of Computer Animation programmes in the UK, the motivation for the creation and development of our centre and its philosophy. In section 3, we outline the degree programmes run by our centre and examine in greater detail the undergraduate programme in question. In section 4 , we discuss what we have learned from designing and running such a programme and in section 5 we examine how this programme is currently being refined and how it is likely to develop in the near future.

In order for such an exposition to be useful to the reader, it requires us to present a fair amount of detail regarding the aims, teaching and assessment methods as well as curriculum content of each individual course (unit) of this programme. Due to space limitations, we have only been able to include such detail in the supplementary material section of this article, which can be accessed online. Such material is generally not made public by most UK universities, as it is considered to be proprietary.

\section{UK Higher Education Courses in CG and CA since the 1970s}

The largest producers of Computer Animation and Digital Effects are the the US, followed closely by the UK and then New Zealand [1]. It is primarily in the US and the UK that the early pioneering developments of these technologies took place. These activities involved the development of various techniques and their creative application in media production.

Computer Graphics (CG) in general and Computer Animation (CA) in particular followed very different development paths in these two countries. Broadly speaking, in the US CG and CA grew within Computer Science Departments and were initially funded by the military $[2,3]$, while in the 
UK these fields grew in Art Departments $[4,5,6]$ and were initially funded by advertising agencies and the production of commercials for television.

This historical accident determined how CG and CA developed in these two countries. In the US computer scientists were in control and the CG field developed more in a photo-realistic direction, while in the UK, artists were in control and the field developed more in a painterly and designerly direction. Of course this is a generalisation, with notable exceptions, and only serves to illustrate the general trend of the two diverse approaches and their parallel development.

Most, but not all, of the early pioneering work was carried out by individuals who worked in universities, some of whom set up their own companies in order to exploit their findings and to engage in the commercial production of computer animated sequences.

It is not surprising then that elements of computer graphics and animation techniques started to appear in the curricula of various university courses in the mid to late 1970s and in the early 1980s. In these early days there was very little differentiation in the use of computer graphics for the purposes of presentation graphics, product or interior visualisation, Computer Aided Design (CAD) and computer animation.

In the UK, this curriculum development took the form of introductory courses in computer graphics techniques in Computer Science and Engineering programmes and in the tentative introduction of computer graphics equipment and techniques to exploit this new technology in the production of art and media artefacts in Art and Design, Media and Architecture programmes.

The initial reaction of the UK's Art establishment to the introduction of this new technology was guarded and unenthusiastic, if not hostile, and a residual degree of scepticism has persisted to date. Ergo the term Computer Art has associated with it some negative connotations in the UK that are absent in the US. The early adopters of the computer graphics technology in the UK were working in the fields of the applied and commercial arts.

In the early to mid 1980s, this new technology started having an impact in Interior and Industrial Design, Graphic Design, Media and Architecture programmes in a few Universities and Art Colleges in this country. Even then, this was a peripheral pursuit only practised by a small and enthusiastic minority of young lecturers and students.

At the same time, what we call today, the computer animation and digital effects industry was beginning to grow around the Soho area of London. In 
those early days in the UK, this industry consisted of a handful of small companies that were set up by enthusiasts in the field. These companies were mainly offshoots of either media or film production companies, or they were boutique companies. Their main clientele consisted of well-established and prestigious London-based advertising agencies as well as various television channels. These companies very quickly became known internationally for their high production values and their creative and innovative use of this new technology. They were predominantly set up and staffed by creative individuals, with an Art or Design background, who were technologically savvy. They needed to be so because at the time there was very little, if any, off-the-shelf software for the high-level production of computer animation. Consequently, most of these individuals, having a creative background, had to teach themselves programming and some mathematics and had to implement what were then state-of-the-art techniques in order to creatively exploit this new technology and to be able to produce computer animation and digital effects. At the time, in a fashion not dissimilar to a significant proportion of computer game production today, every new production necessitated an almost complete rewrite of the software needed to achieve the desired result.

One of the limiting factors to the growth of this burgeoning industry was the almost total absence of dedicated courses for the teaching of computer animation techniques and the formation of graduates with a well-rounded education who could meet the needs of this industry. There were a few notable exceptions to this, however. The universities of Middlesex, Teesside and Bournemouth had implemented pathways in various Art, Design and Media degrees that covered computer graphics and animation techniques to some extent. These universities were beginning to build a name for themselves and to acquire a reputation in this field.

In the early years of the development of Computer Animation there was a dearth of off-the-shelf software for production or even for teaching. Consequently, we had to develop our own home-grown system called CGAL $[7,8,9,10]$, which was used for teaching and production. This system was first conceived in the late 1970s and continued to develop until the late 1990s, becoming a very complex and sophisticated piece of software with a very powerful scripting language. In the early 1990s, it was commercialised and sold internationally, thus becoming the only 3D Computer Animation system to be exported from the UK.

In the 90s, the demand for skilled computer graphics and animation practitioners expanded rapidly. This was partially due to the emergence of 3D 
computer games, the production of which requires the creation of $3 \mathrm{D}$ animated assets. Despite the apparent differences between Computer Animation, Digital Effects and Computer Games, the underlying technology and techniques used in the production of artefacts is very similar. This makes it necessary for practitioners in these industries to posses an identical skill-set [11].

The unprecedented growth of the computer animation and games industry since the late 90 s has led to an explosive growth in UK degree programmes with the tag "Computer Animation" or "Computer Games" in their title [12]. For instance, currently there are in excess of 160 Computer Games and 120 Computer Animation related degree programmes in the UK [13]. For many of these, a large proportion of which is offered by UK HE institutions, their computer animation or computer games component constitutes only a minor option of the programme which is combined with other more established - and often unrelated - subjects. In some instances, universities use the "Computer Animation" or "Computer Games" buzzwords to market programmes with a declining popularity. In recent years, most Computer Science departments have witnessed a dramatic decline in applications and even some Art departments have witnessed a less marked but steady decline. This has led some such departments to tweak or cosmetically modify some of their existing programmes to include some "Computer Animation" or "Computer Games" options. Most of these programmes concentrate primarily on the creative aspects and applications of the computer animation production process or the computer game development process and cover subjects such as game design or the art and animation production processes.

The alarming growth of such programmes has led to the development of SkillSet. SkillSet is the Sector Skills Council (SSC) for the Creative Media (http://www.skillset.org). It is a government-funded body that, among other things, monitors course standards in Animation and Games and accredits university degree programmes through the use of an academic and industry peer review process. This accreditation can only take place a year after a programme has produced its first graduates, in order for SkillSet to be able to ascertain graduate employability. After that these programmes are re-accredited on a yearly basis. This is currently a voluntary process that universities submit themselves to. Thus far only eight Animation and nine Games programmes have been accredited by SkillSet. 


\subsection{The Creation and Development of the NCCA}

By the end of the 1980s, it became apparent to us that something needed to be done to accelerate the development of specialist university degree programmes that were specifically designed to produce graduates that would be able to both advance the field of computer animation and who would posses the necessary qualities and skills required for commercial computer animation production.

From our personal experience in production and by analysing the industry needs we came to the realisation that what was required was to produce graduates that were a hybrid between an artist and a scientist / technologist. What we had to do next was to convince our university that this goal was both desirable and achievable, while at the same time securing the support of our industry and hopefully convincing academics in other universities to also adopt this approach of interdisciplinary / multidisciplinary education. The latter would prove to be the hardest to achieve and even after we successfully implemented such degree programmes most of our colleagues from other universities did not follow suit.

Our approach, although it may have appeared revolutionary at the time, was not without precedent. Architecture is the obvious example of an interdisciplinary / multidisciplinary field that is well established and no longer raises any eyebrows. Like an architect, a computer animator needs to have a mixture of creative and technical aptitudes and skills. An architect needs to have a facility in both Art and Science in order to design a building that is both aesthetically pleasing and structurally sound. Similarly, a computer animator needs to be able to use the existing technology creatively, but he also needs to understand this technology so that he can push it to its limit and even to shape its development in order to produce state-of-the-art results.

In the autumn of 1989, two members of the Division of Computer Graphics of Bournemouth University convoked a working group of experts in order to examine the nascent state of Computer Animation education in the UK and to determine how it could be improved in order to help the development of the Computer Animation and Digital Effects industry. This panel of experts consisted of a representative sample of leading academics in the Computer Graphics production discipline, representatives from the newly emerging Computer Animation and Digital Effects production companies and representatives from the Computer Manufacturing industry.

At the first meeting of this group a consensus quickly arose that there was a dearth of courses in the area of Computer Animation and that prac- 
tically no research in this area was being carried out in UK universities. The group felt that in order to facilitate and encourage the growth of Computer Animation in the UK, what was needed was the creation of a "Centre of Excellence" that would be able to lead the development of both undergraduate and postgraduate courses, and to conduct academic research and near-market research (what is today referred to as Knowledge Transfer). It was agreed that such a centre would be known as "The National Centre for Computer Animation". Following its first meeting, this working group was renamed the NCCA Establishment Board.

After due consideration of the expertise of teams of academics from various educational institutions, and following protracted discussions and negotiations, it was finally agreed by this board that the team of the Computer Graphics Division at Bournemouth University would be given the task to implement the concept of the NCCA. The board stipulated that this "title of distinction" be awarded to the Division of Computer Graphics and its staff while they continued to actively pursue the goals of the NCCA.

Since setting up such a centre would involve a substantial investment from Bournemouth University, the university authorities had to be consulted and to agree to the establishment of this centre and to recognise the NCCA as a centre of excellence of the University. Following this, the University management had the legitimacy of the NCCA title checked and approved by the Department of Education.

The NCCA was formally established in late 1989 with a substantial investment from the University, which was more than matched by a number of substantial donations of hardware and software from various companies, including Apollo Computer Inc., Hewlett-Packard Inc., Silicon Graphics Inc., $\mathrm{ABC}$ Ltd. and Alias Inc.

Since then, the NCCA epithet has been used to refer to both our teaching and research activities in Computer Animation and is an umbrella title for both our academic and our research activities.

In 1989, Apollo Computer Inc. endowed the Apollo Chair of Computer Animation to the Director of the NCCA. This was the only such chair that Apollo Computer Inc. awarded internationally. Subsequently, this chair was sponsored by Hewlett-Packard Inc. and ABC Ltd.

Also in 1989, we launched the first Computer Animation Masters programme in the UK and perhaps the world. This MA programme quickly became internationally acclaimed, as it was the first Masters degree specifically aimed at producing Technical Directors and 3D Computer Animators. 
This programme was distinguished by the fact that it consisted of a 50-50 mix of Art and Science.

In the spring of 1990, the then Under-Secretary of State for Higher Education presided over the inauguration of the purpose-built NCCA Animation Lab.

In 1992 we launched a new Bachelors degree which followed the same philosophy as our Masters degree. This degree and its development is the subject of this paper.

On the research front the success of the NCCA researchers can be measured in terms of the RAE. The UK Government has created a mechanism for measuring the value and effectiveness of UK universities in various fields of research. This mechanism is called the Research Assessment Exercise (RAE).

The RAE takes place every four or five years and awards university departments a research grade between 1 and $5^{*}, 5^{*}$ being the best grade and indicating that the research of a given department is of international significance. Achieving a high score in the RAE has positive prestige and financial implications for a university department and it is highly valued by universities. The RAE score is based exclusively on peer assessment of research outputs and various other esteem indicators, which show how the research of each department influences and impacts on its field of expertise. In the future, the RAE is going to be replaced by a Research Excellence Framework (REF) [14] that will provide a revised mechanism for measuring research activities of UK universities.

Our research team has achieved consistently high scores in successive RAEs thus making it the highest rated UK research team in the field of Computer Animation. Our team's scores have been 4 (in 1992), 4 (in 1996), 5 (in 2001) and the equivalent of a $5^{*}$ (in 2008).

In the early to mid 1990s, members of our team, under the guise of a University owned consultancy company called "The Cupboard", started producing a series of Computer Animation Ride Simulations for various companies, including the Astronaut Hall of Fame in Florida. We were the first group in the UK to attempt such a challenging feat. These productions acted as a vehicle for "Knowledge Transfer" and "Practice Based Research" activities.

In 2007, the 3D World magazine assembled an international panel of Computer Animation and Games experts in order to grade the provision of various educational institutions in the UK and abroad. The NCCA was ranked the number one institution for the provision of Computer Animation education in the UK. The accompanying article stated that the NCCA is 
"one of the most famous and dependable sources of animation talent in the UK. Graduates can be found working at major studios world-wide" [15].

This accolade was repeated almost a year later, when the NCCA was also rated as the eighth best institution internationally in terms of international Animation Festival entries [16].

\subsection{The NCCA and its Philosophy}

Since its inception, the philosophy of our centre has been to marry Art and Science in order to facilitate the production of Computer Animation, Digital Effects and Computer Games. Our centre is truly interdisciplinary and is populated by an integrated team of technical and creative people. Our motto is "Science in the service of the Arts" and reflects our attitude towards the mix of the arts and sciences in our teaching and research. To achieve this we have designed undergraduate and postgraduate degrees that expose students to and that expect them to excel in both the technical and creative aspects of our discipline. These programmes aim to develop in students an interdisciplinary culture that transcends the Art / Science divide by developing their creative design skills as well as their programming and mathematical skills, which entry level digital artists should possess [17, 18]. We do not believe that artists should just be consumers and users of technology but should have a sound understanding of it and be able to influence and contribute to its development. They should not just be tool-users, but toolmakers as well. Like renaissance artists had to understand (and frequently invent) the tools and paint technology that they used for the production of ground-breaking pieces of art, so (we believe) should our students understand the mathematics and algorithms underlying the tools that they use in their electronic productions. This understanding makes them better problem solvers and production artists, and allows them to exploit the full potential of these tools. By being able to write scripts and programs, our students are able to modify and extend existing tools and thus their artistic abilities are not limited by the existing technology. Additionally, by speaking the language of the computing R\&D people in their production teams they can better explain how software tools can be modified and improved.

\section{The Degree Programmes of the NCCA}

Our centre currently runs a Bachelor of Arts (BA) degree in Computer Visualisation and Animation (with a population of 150 students) and three 
Masters degrees: a Master of Arts (MA) in 3D Computer Animation, an MA in Digital Effects and a Master of Science (MSc) in Computer Animation, Games and Effects (with a combined population of 80 students). We also have a dozen PhD students working mainly on the technical side of Computer Animation and Computer Games.

Our MA degrees were designed for graduates with a BA in Traditional Animation, Fine Art, Graphic Design, Photography, Film and related disciplines. Our MA programmes aim to enable these graduates to become competent practitioners in Computer Animation and Digital Effects by enabling them to exploit their existing experience using Computer Animation and Digital Effects tools. Students on our MA programmes are introduced to both the technical and creative aspects of Computer Animation and Digital Effects in parallel. Graduates of these programmes are primarily creative users of existing animation and effects systems and tools.

Our MSc degree was designed for graduates with a BSc in Computing, Mathematics, Engineering and related disciplines. Our MSc programme aims to enable these graduates to become competent Technical Directors (TDs) and software tool developers in the areas of Computer Animation, Computer Games and Digital Effects. Students on our MSc programme are introduced to both the technical and creative aspects of Computer Animation, Computer Games and Digital Effects in parallel, and they are encouraged to collaborate with our MA students in production projects. Graduates of this programme are primarily technical users of existing animation and effects systems and tools and developers of new software tools.

In order to get a better understanding of our approach to educating technophile artists, let us consider as an example our Bachelor of Arts programme in Computer Visualisation and Animation (BA-CVA) in more detail.

\subsection{The Creation of the BA-CVA}

This degree programme has been running since 1992 and we have gained significant experience in running such interdisciplinary degrees that transcend the Art / Science divide.

This programme is fairly unusual in the UK in that it is something between a Bachelor of Science and a Bachelor of Arts. Applicants to this degree are required to have post-sixteen qualifications (A-levels) in both creative and technical subjects. All shortlisted applicants are required to have obtained A-levels in Art, Photography or Design and in Mathematics, Physics or Computing. The candidate selection process involves entrance tests in 
life drawing, mathematics and logic, the presentation of a portfolio of creative work and a rigorous interview process to determine their motivation, understanding of the discipline and suitability for the programme.

This programme has the highest entry requirement of all UK Computer Animation Bachelors programmes and is one of only two 3D Computer Animation degree courses accredited by SkillSet.

\subsection{The Nature of the BA-CVA}

The nature of our degree is such that the students are exposed to a combination of technical and creative subjects, which cover most of the core areas of the computer graphics knowledge base developed by Orr et al. [19]. Teaching on this undergraduate degree is structured in a manner that is closer to a breadth-first approach [20], rather than the bottom-up or topdown approaches [21] often encountered in computer graphics courses that are embedded in computer science degree programmes. Our degree produces graduates that very much have the combination of artistic and technical problem solving skills called for by McCracken [22]. On the technical side of the programme students are exposed to Mathematical and Algorithmic Techniques for Computer Graphics [23], Computer Programming, Principles of Computer System Design and Operating Systems. On the creative side of the programme they are exposed to the History of Art, Film and Animation, Art Practice and Experimentation, Film Studies [24], Motion Studies, Animation Studies and Character Design. Finally on the production side of the programme, which integrates the creative and technical sides, they are exposed to the use of Computer Animation systems including Scripting, Modelling and Animation. All components of the degree programme are fairly comprehensive, for instance, in the Mathematical and Algorithmic Techniques for Computer Graphics course of the degree we start by covering some basic concepts of Geometry, Trigonometry and Number Theory and we quickly progress to Set and Function Theory, Vector and Matrix Algebra, Transformations, Clipping, Lighting, Rendering, 3D Textures, the mathematics of Curves, Surfaces and Volumes, 3D Deformations, Particle Systems etc.

An integral component of this course is the project work that the students have to undertake, which includes technical programming projects and creative animation projects, as well as industry-led Master Classes and experimental/research projects that allow students to engage with some experimental techniques and perhaps fail creatively or technically without being 
penalised for trying something too ambitious or for experimenting with an untried technique. Some of these projects are undertaken in groups, to prepare students for the practices of our industry. Finally, an individual project constitutes a large part of the final year of the degree.

\subsubsection{Units (Courses) in our current BA-CVA Programme}

The curriculum of our current BA-CVA programme is outlined in Table 1, which should be self-explanatory. A more detailed explanation of each individual unit (course) of the programme can be found in section A of the supplemental material for this article.

\subsection{The BA-CVA Final Year (Major) Project}

The major project undertaken by BA-CVA students in the final year of their studies enables them to concentrate on the development of those skills that allow them to specialise in different areas of computer animation production.

To permit this level of specialisation, the procedure adopted for this project is as follows. Each student produces an initial pitch, which is presented to the entire faculty project-supervising team. This presentation is followed by the assignment of a personal supervisor to each student. Together with the supervising faculty member, the student then produces a more refined and formal brief for his or her project, which sets out the criteria against which this student wishes to be assessed. These criteria must include a percentage weighting factor for the technical component of the project, one for the artistic component and one for the final project report / thesis.

Examples of student project-work from our programmes can be found at the following links: http://ncca.bournemouth.ac.uk/ and http://www.youtube.com/user/NCCAAnimation.

In order to illustrate the range of final year projects that our students undertake we will examine in some detail two such projects.

\subsubsection{The "Harvester" Project}

The first project concerns the production of a short narrative animation piece entitled "Harvester". The animation depicts a character entering a forest, collecting magical fruits, being chased by the spirits of the fruit trees and eventually being punished by the spirit of the earth itself (Figure 1).

This piece looks deceptively simple but required the solution of a number of complex technical problems for its production. The main character of the 
piece, although rendered in silhouette form, was modelled, rigged and animated in 3D using Maya. The terrain and the trunks of the trees were handmodelled, rigged and animated in 2.5D using Maya. The tree branches and ground foliage were captured through digital photographs and video, cleaned up and used as texture plates. These were used to texture image planes which were attached manually to the rigged tree branches. The spirits of the trees were modelled, animated and rendered using Houdini. The tree dissolving into smoke and the collapsing earth were modelled using Houdini's smoke solving system and some procedural animation in Houdini, respectively. Finally, all the rendering passes were integrated using Shake. Post-processing for the light bloom with shadowing for the character and other moving parts of the scene was also done in Shake.

This is a good example of what our best students can achieve. They can seamlessly combine character animation with technical direction to achieve the desired production results. Nicholas Hampshire, whose final year project this was, has since completed an MSc in Computer Animation, Games and Effects at the NCCA and he is currently working in industry. "Harvester" was shown at the Edinburgh International Film Festival 2009. This animation can be found at: http://www.youtube.com/watch?v=prnSJjPjvX0

\subsubsection{The "Black Skies" Game Engine Project}

The second project concerns the development of a game engine prototype that provides all the basic features expected of a rudimentary game engine and many features that are only found in cutting-edge blockbuster game titles (Figure 2). The engine, which was developed in $\mathrm{C}++$, incorporates the following features: a 'next generation' renderer that allows for the use of high quality shader effects and post-production techniques, scene management for large outdoor environments, skinned animated meshes created on the CPU or the GPU, a sound engine allowing the user to load and play audio files, a GUI module that allows for basic point and click interaction and the rendering of text on the screen, optimisations for current hardware (such as GPGPU and multithreading), the use of an industry standard graphics API (such as OpenGL 3.x or DirectX 10.1) and a minimum frame rate of 25 fps on middle-range hardware (in this case an NVIDIA 8800GTX).

The various visual effects that were implemented in this game engine include: large terrain rendering, grass rendering at various LODs, animated water rendering with reflection, refraction and interactions with the terrain, bloom-effect rendering, fog-effect rendering, the rendering of crepuscular 
rays, the rendering of screen distortion effects (such as rain droplets running down the camera lens and cracking or shattering of the camera lens), the rendering of shadows and ambient occlusion.

When Simon Roth, whose final year project this was, first joined our BACVA programme he would have described himself as an artist, but he has developed into a very competent software writer, with a wonderful eye for visual effects, and he is about to embark on a four-year Industrial Doctorate at the NCCA in collaboration with a well known UK computer games company. A real-time recording demonstrating the capabilities of this game engine can be found at: http://www.youtube.com/watch?v=SiXDydvV92k

\subsection{Infrastructure and Support}

An important factor for the success of the BA-CVA is the environment in which learning takes place. Each year group has 24-hour access to its own dedicated animation studio (computer lab). This studio atmosphere fosters an ethos of collaboration rather than competition between students. We feel that this is vital because it allows students to continue their learning outside of lecture and workshop times, within an environment specifically suited to their needs. Further, a great deal of the work that students undertake is project-based, which must largely be completed outside of lecture-times. This 24-hour access is also well attuned to the generally observed student working habits of completing such work in the evenings / early-mornings.

The lab equipment consists of workstations with multiple processing cores and high-end professional-line graphics cards, with the final-year machines having the highest specification. The ratio of students to workstations is two to one. The operating system currently used is Linux, although a number of Windows and Apple computers are also provided in each lab for generalpurpose use with specialist software. For the BA, the 3D software that is primarily used is Maya, although some classes are based on Houdini. Other software that students have access to includes Renderman and Massive. Students also have access to an in-house render farm, with scheduling based on a usage-priority system that favours students who use it less.

Our students also have access to a full-blown Motion Capture studio based on the Vicon optical system and our home-grown Motion Capture pipeline toolkit, which is a new MoCap Character Animation environment developed by NCCA researchers.

For teaching and practising traditional arts skills, there is also a wet-room studio for life-drawing, sculpting, model-making etc. 
The NCCA faculty consists of a team of twenty six artists, computing and technology experts working collaboratively in the research and teaching of Computer Animation, Digital Effects and Games. The balance between the creative and technical skills of the team varies periodically but is approximately balanced. The artistic members of our team have an affinity for the technology and analogously the technical members of our team have an affinity for the arts. All members of the team are encouraged to pursue both teaching and research in parallel, but some tend to gravitate more towards one activity rather than the other.

Expert support is also available to students in the form of demonstrators, many of whom are graduates of our degree programmes who have returned to the NCCA after spending some time in industry. The demonstrators assist with workshop sessions and are available outside of lecture-times for general purpose trouble-shooting and advice.

In addition to this we employ a mentoring scheme dubbed PAL (PeerAssisted Learning), which involves students at a senior level of the Bachelors degree mentoring students of the years below. We find that this scheme is particularly effective, as students who have questions or who face difficulties with their work often find it easier to approach their peers in the first instance before they approach members of the faculty. Furthermore, this scheme encourages students to interact with others in their peer-group who have faced similar difficulties in the past and have managed to overcome them. We have found that this scheme reinforces the team spirit that we instil among our students, as it encourages them to become self-reliant independent learners and ultimately improves the retention rates of first year students. The students that act as mentors, selected from the students of a senior year, receive appropriate training and are paid for the mentoring sessions that they take part in.

\subsection{Graduate Destinations}

Because of the nature of their education, the majority of our graduates end up working as Technical Directors (TDs) in the Effects and Animation industry and as Technical Artists (TAs) in the Computer Games industry.

Graduates of the BA-CVA programme have an excellent employment record and most are employed within a few days or weeks after graduation. It is not uncommon for the best of our students to secure job offers - often from more than one company - even before they have sat their final examinations. In order to determine the long-term career trajectories 
of the BA-CVA programme graduates and to gain a better measure of the effectiveness of this programme in preparing our graduates for positions with management responsibility in our target industry, in March 2009 we conducted an informal and non-exhaustive survey of a representative selection of our alumni. For the purposes of this survey we have defined a management position to be a position in which an individual has responsibility for directing, leading or supervising the work of other colleagues. These roles include in their titles words such as Senior, Lead, Supervisor, Head, Director, Owner and other derivative terms. The results of this non-exhaustive survey show that significant number of BA-CVA programme graduates hold management positions in the CG industry internationally. In a number of instances our graduates have progressed to these positions of responsibility within a few years of graduating.

This survey revealed that indicative job titles for our graduates are (in no particular order): CG Supervisor, Lead Shader Writer, Lead Look Developer, Head of Cloth and Hair, Head of Rigging, Head of Lighting, Lead Character Modeller, R\&D Co-ordinator, Head of 2D, Head of 3D, Head of R\&D, 3D Sequence Lead, FX Lead, VFX Lead, Lead Animator, Lead Animator \& Character TD, Consulting Digital Supervisor, Senior Compositor, Senior Programmer, Senior Technical Artist, Senior Character Artist, etc.

Also an indicative list of companies where our graduates are employed includes (in no particular order): Pixar, ILM, Sony Imageworks, Dreamworks Animation (LA \& SF), Weta Digital, Animal Logic, Image Engine, Rising Sun Pictures, MPC, Double Negative, Framestore, Glassworks, Rushes, 4:2:2 South, Sony Computer Entertainment Europe, Electronic Arts, Lionhead Studios, Rare, Codemasters, Frontier Developments, AiLive, Artificial Mind \& Movement, Pandemic, etc.

If one wished to evaluate the contribution that the NCCA, its philosophy and its graduates have made to the success of our industry internationally, one need look no further than at some of the latest animation / digital effects block-buster films such as Avatar [25] and Star Trek [26] - both of which were nominated for the Academy (Oscar) and BAFTA (British Academy of Film and Television Arts) awards. An NCCA graduate, Paul Kavanagh, acted as one of two animation supervisors for Avatar and as the animation supervisor for Star Trek, for which he was named in the Visual Effects Oscar nomination. Additionally, fifty-five NCCA graduates worked on the digital effects team for Avatar. A non-exhaustive list of other NCCA graduates and ex staff success stories for this year includes: Willi Geiger who worked as CG supervisor for 
Harry Potter and the Half-Blood Prince [27], Nigel Sumner who worked as CG supervisor for Star Trek and Lee Uren who worked as lead digital artist for Terminator Salvation [28].

\section{Discussion}

Thanks to our interdisciplinary approach, we believe that we have found solutions for problems that have been identified by other authors long after we designed and successfully ran our degree programmes [29, 30, 31, 32]. Attempting to teach an interdisciplinary course can create a wide variety of issues, however, not least of which is ensuring that students actually receive the balance of education that was intended for them.

It is our observation that students tend to gravitate towards one discipline or the other, some to a greater extent than others. While we believe it is important for students to find their own specialist areas, we do not believe that this should be at the expense of a broader interdisciplinary education. Our Bachelors degree programme is designed to start with a broad approach and covers a wide range of topics in the first year, before encouraging students to investigate specialist subjects in the second year and finally to pursue them at a greater depth in the third year, culminating in the third-year major project which is entirely student-led but approved and supervised by faculty members.

The difficulty then remains as to how to generate and maintain an interest in both Art and Science during the initial years, before students have developed specialist interests and before they are fully aware of all the topics that might be of interest to them in the future or be fully cognisant of the connections between seemingly unrelated topics. This is a difficult and ongoing problem which, to a large extent, must be addressed at the delivery-level. For example, when introducing a new topic within a given subject area it is important to place this in context within the wider discipline and to identify links which, although they may seem obvious to the faculty member, may not be readily identified by students. It is a general observation that students may not be keen to engage with subject areas for which they fail to recognise their relevance.

Another example for this is the concern that students can have for the relevance of the curriculum content to their future employment. We believe that this is often due to the fact that more often than not undergraduate students find it hard to distinguish between education and training. While 
in general this problem is not restricted to interdisciplinary programmes, it can be more acute in such programmes. For instance, a student with an art-bias and an intention to enter into the industry as an animation artist may express an antipathy towards the more mathematical or programming content of the programme and to question the relevance of this content to their chosen career path, which "may be grounded in a general misconception of computer science and programming among ... students" [33]. However, attitudes such as this reinforce the Art / Science divide and - more to the point - go contrary to the objective of the course to create interdisciplinarians rather than just artists. To clarify, we are not saying that being an artist is in any way inferior or undesirable but that, especially given the nature of our industry, we believe that being an interdisciplinarian is even more desirable.

Although we believe that procedural literacy [34] is in itself vitally important for new media practitioners, this is not the only reason why computer programming is taught at the NCCA. Far more important is the application of the teaching of computer programming for schooling students in how to "think effectively" [35], i.e. in a logical fashion. Computer programming is far more valuable as a mental exercise rather than if it were only to be used as a tool, as then it can be instrumental in the development of creative thinking. Like Allen et al., we believe the learning of programming concepts "can provide insight into not just the field of computer science, but in virtually every modern field of human endeavor. It can therefore increase students' intellectual depth and help them to think productively in many different contexts"[36]. In our case, gaining this technical perspective enables our students to be much more proficient problem solvers when it comes to finding solutions in computer graphics and animation production, than if they lacked this interdisciplinary education.

Equally, we believe that students with a technical bias need to engage with the visual studies, cinematography and life drawing components of the curriculum in order to develop their sense of aesthetics and to learn to communicate visually with their more artistically biased peers.

It is important then to reinforce the interdisciplinary philosophy and we have found that a good way of doing this is through our industry contacts - often with our own alumni. It is often the case that a single conversation with an industry practitioner, who could say exactly the same things as a faculty member but with 'real-world' anecdotes and first-hand examples, is effective in convincing students of the merits of a topic they may had previously discounted as being irrelevant. Indeed, talking with our industry- 
employed graduates has led to many apparently surprising revelations, such as those from individuals who now regularly write programs / scripts and solve mathematical problems in an animation production context although they originally considered themselves as being art-biased when they first started out. Such examples are unexpected for the students and, in some instances, even for the industry practitioners themselves.

Close involvement with industry has been vital to the NCCA since its creation and is extremely popular with students. The NCCA runs a weekly guest-lecture series, where invited industry speakers talk on a range of topics, from previous works to techniques and tips to advice on entering the industry. It should be noted, however, that the needs and expectations of different companies can vary and often appear contradictory, especially depending on which roles a company is currently looking to recruit for. Industry speakers and Master Classes do provide students with a valuable insight into the industry from an early stage of their studies, which can allow our students to 'hit the ground running' as soon as they find employment after graduating.

One important link with industry practices is the use of group work. The benefits are wide ranging and include allowing students to investigate areas of specialisation, how they interact with each other and the impact on the work-flow and how to manage this. Workload management is always difficult in a group environment and presents challenges to the examining team. The approach we use varies on a case-to-case basis and it is led by the group's supervising faculty member.

In general, though, assessing creative and technical content on an interdisciplinary course can also introduce challenges that must be overcome. Programme units which address a specific aspect of the curriculum, such as life-drawing or mathematics, are generally less of a problem than assessing projects which tend to synthesise the curriculum's various aspects and learning outcomes. Here, it is necessary to objectively assess the artistic and the technical aspects, and everything that is in-between, so as to arrive at a single final mark.

Production projects, especially the final year major projects, are assessed by a group of faculty members that have a mix of expertise on both the creative and technical aspects of the discipline. 


\section{Current and Future Development of the NCCA's Degrees}

The rapidly changing nature of our field requires educators to keep abreast of the latest developments and trends, so that we can anticipate future needs and adjust our degree programmes accordingly. Regular course reviews, as required by UK institutions, allow more significant changes to be adopted. All programmes of the NCCA have recently undergone a complete course re-design and re-validation, during which process the design team debated and evaluated the merits of a wide variety of changes and refinements - some more radical than others.

In our discussions we first considered the interdisciplinary nature of our BA programme. We very quickly came to the conclusion that the overwhelming majority of the faculty wished to retain this interdisciplinarity as we continue to believe that the new discipline of Computer Animation has emerged from the fusion the disciplines of Art and Computing. We also felt that our approach to the teaching of Computer Animation gave us a competitive advantage in the UK university sector and allowed us to produce graduates with a rounded education that also possessed both transferable and practical skills that made them very desirable to our industry. As was mentioned before, approximately $50 \%$ of our graduates are employed as TDs in the Computer Animation and Digital Effects industry and the remaining $50 \%$ are employed as TAs in the Computer Games industry.

Then we discussed at length the structure of the BA-CVA programme. This debate was focussed upon the competing concepts of generalism versus specialism. Some members of the faculty felt that the structure of the BACVA programme was biased towards producing generalists despite the option offered to the students to specialise through the selection of appropriate projects in the second and third years of the programme. They also felt that the BA-CVA programme, while good at producing TDs and TAs, was not ideally suited for producing character animators or animation directors.

This discussion took place in the context of a wider consultation with some of the most influential leaders of our industry. The industry opinions and suggestions were often contradictory. In general however we discovered that our industry was very happy with the quality of the graduates produced by our centre, but that they faced a shortage of specialists in other areas. In summary one can distil their arguments and needs as follows.

Computer Animation and Digital Effects companies, as well as Computer Games companies need to employ three types of specialists for production. 
On the one extreme, they require artists with a superficial understanding of technology (i.e. technology-nave artists) to act as character animators and animation directors. On the other extreme, they require computer scientists with a superficial understanding of art (i.e. art-nave technologists) to work in their R\&D departments. But, predominantly they require interdisciplinarians (technology-savvy artists) to act as TDs or TAs. This third category is quite broad and can cover the entire range from very technical to very creative TDs and TAs.

It is our understanding that, at least in the UK, in current productions the ratio of the three categories of specialists is one $R \& D$ specialist to every eight TDs / TAs and every two character animators. We also understand that the Computer Animation and Digital Effects industry finds it hard to recruit good home-grown character animators and that the Computer Games industry finds it hard to recruit good computer scientists with relevant knowledge of CG techniques and experience in implementing them in a production environment. While industry representatives recognised that our undergraduate programme produced very accomplished TDs and TAs, they wondered if we could expand the range of our courses in order to produce graduates in the other two categories; indeed they urged us to do so.

After extensive discussion and careful deliberation our faculty decided to rise to the challenge laid down by our industry. We agreed that we would double our undergraduate intake, while at the same time refining the structure and expanding the scope of our undergraduate provision. To achieve this we had to design an undergraduate framework in Computer Animation, Games and Effects, consisting of three closely related Bachelors programmes. A BSc in Software Development for Animation, Games and Effects (BSc-SDAGE) and two BA programmes: the BA in Computer Visualisation and Animation (BA-CVA) and the BA in Computer Animation Art (BA-CAA). The structure and close interrelationship of these three programmes is shown in the framework structure diagram in Table 2.

This framework is composed of five parallel streams, appearing as columns in this diagram, labelled 1 through 5 . The columns on the left of this diagram represent the technical units, while the columns on the right of the diagram represent the creative units (with the exception of the entries of the first year in column 5). Finally, the middle column of the diagram represents the production-based units that bring together the students from all three programmes. Thus, BSc-SDAGE students study the units in columns 1, 2 and 3; BA-CVA students study the units in columns 2, 3 and 4; and BA-CAA 
students study the units in columns 3,4 and 5 .

This design has the added benefit of preserving our old-style BA-CVA almost unchanged, but more importantly it has the advantage of allowing "art-naïve technologists", "technology-savvy artists" and "technologynaïve artists" to collaborate in the production of CG artefacts. Additionally, through osmosis this design allows students to develop an affinity for each other's culture and a healthy respect for the talents and knowledge of those that come from a different area of expertise. This integrative experience replicates what they would have to do when working in industry after graduating and will culminate in transforming these individuals into a group of "technophile artists" and "artophile technologists" (to coin a neologism).

Thus, we aim to produce artists that have an affinity for and can use technology effectively in CG artefact production, technology-savvy artists that are able to find both artistic and technological solutions to CG artefact production problems and technologists that have an affinity for $\mathrm{CG}$ artefact production and can develop software tools to facilitate such production.

While this streaming may at first appear to be contradictory to the entire philosophy of the NCCA, this is not the case. This was not an argument for or against interdisciplinarity, but rather an argument about the nature of the graduates that the original BA-CVA programme produced. Should our graduates be generalists or specialists? Given that the BA-CVA programme affords our students some opportunity to specialise, does its structure posses sufficient flexibility to allow our students to specialise equally whether they be artistically-biased or technologically-biased? These were the deliberations that led us to introduction of streams.

In designing our new undergraduate programme framework we attempted to retain a balance between developing a set of degree programmes that are well-rounded, academically stimulating and challenging, capable of producing self motivated learners and problem solvers, while at the same producing graduates that meet our industry's employment needs.

More specifically, the BA-CAA programme is aimed at individuals who wish to develop an expertise in the creative aspects of CG artefact production while at the same time having a comprehensive understanding of the tools and techniques necessary for such productions. Graduates of this programme are likely to gain employment as Compositors, Character Animators, Matte Painters, Concept Designers and Animation Directors.

The BA-CVA programme is aimed at individuals who wish to gain an in-depth understanding of the creative and technical aspects of CG artefact 
production and become able to develop original creative or technological solutions to CG production related problems. Graduates of this programme are likely to gain employment as TDs or TAs.

The BSc-SDAGE programme is aimed at individuals who wish to become computer technologists with a comprehensive mastery of CG techniques, able to design and implement software tools for CG productions while at the same time having an affinity for CG art and a good understanding of how CG artists work. Graduates of this programme are likely to gain employment as CG software developers or members of the R\&D team of an animation, effects or games production house.

A more detailed explanation of the individual units of these programmes can be found in section B of the supplemental material of this article.

Next year, we intend to implement an additional structural change to our undergraduate programme framework by introducing a fourth, Masters level, year. With these new four-year programmes, students will have the opportunity to graduate with a BA / BSc after completing three years of study or they could elect to undertake a fourth year of study and graduate with an MA / MSc. This degree programme format conforms to the requirements of the Bologna Agreement [32]. Additionally it has the advantage that it makes it easier for students to secure funding for a Masters programme from the supporting financial bodies. Finally, it provides tailor-made Masters programmes for our Bachelors graduates. As was mentioned before in section 3, our current Masters programmes were designed for Bachelors graduates from other disciplines entering our discipline and thus they are not ideally suited for Bachelors graduates from our own BA / BSc programmes. Be that as it may, in the past a proportion of our BA graduates have elected to enrol on our existing Masters programmes.

\section{Conclusion}

In this paper we have examined the state of CG education in the UK before the NCCA was created concentrating primarily on Art \& Design education, but also examining Computer Science education. We have then examined what motivated the creation of the NCCA and outlined its structure, its philosophy and teaching and research activities.

The central theme of this paper concerns the creation of the first UK interdisciplinary Bachelors programme in Computer Animation. We examined its philosophy and structure, we described its curriculum, we commented on 
the resources needed to deliver this programme, we remarked on its graduate destinations and we have outlined how it will evolve and change in the coming academic year.

In conclusion we would like to suggest that the main reason for the longevity and acknowledged success of the BA-CVA programme is its interdisciplinary nature and its innovative, deliberate and well-considered design. We hope that this paper will help inspire our colleagues internationally and will encourage them to develop similar programmes for the teaching of Computer Animation, Digital Effects and Computer Games.

\section{Acknowledgements}

We would like to express our gratitude to all our colleagues at the NCCA. Without their tireless dedication, determination and hard work none of this would have been possible. We would like to single out Peter Hardie (recently retired) who, together with Peter Comninos, created the NCCA and helped design the original BA-CVA programme.

Last but not least, we would like to thank our alumni and students who over the past eighteen years have worked hard, excelled, contributed to the development of our industry and helped build the reputation of the NCCA and of the BA-CVA programme. We would like to single out Nicholas Hampshire and Simon Roth for the use of their images and for being such hardworking and talented students.

\section{References}

[1] UK Film Council . Post-production in the UK. Department of Trade and Industry; 2003.

[2] Computer Science and Telecommunications Board (CSTB), National Research Council . Funding a Revolution: Government Support for Computing Research. National Academy Press; 1999.

[3] Parent R. Computer animation: Algorithms and techniques - a historical review. In: CA '00: Proceedings of the Computer Animation 2000 Conference. IEEE Computer Society; 2000, p. 86-90.

[4] Mason C. A computer in the art room. In: Proceedings of CHArt Conference 2004 - Futures Past: Twenty Years of Arts Computing. 2004. 
[5] Mason C. A Computer in the Art Room: The Origins of British Computer Arts 1950-1980. Quiller Press; 2008.

[6] Brown P, Gere C, Lambert N, Mason C, editors. White Heat Cold Logic: British Computer Art 1960-1980. The MIT Press; 2009.

[7] Comninos P, Webster G. CGAL: Computer Graphics and Animation Language. In: Eurographics Conference Proceedings. 1980, p. 113-26.

[8] Comninos P. Computer Animation in Interior and Industrial Design. Computers \& Graphics 1985;9(4):449-53.

[9] Comninos P. The CGAL Animation Environment and its Application in the Entertainment Industry. In: Procceedings of the International Electronic Image Week, Second Image Symposium. 1986, p. 324-32.

[10] Comninos P. Computer Graphics and Animation for Interior and Industrial Designers. In: Lansdown J, Earnshaw RA, editors. Computers in Art, Design and Animation. Springer-Verlag; 1989, p. 216-24.

[11] Anderson EF, Engel S, McLoughlin L, Comninos P. The case for research in game engine architecture. In: Future Play '08: Proceedings of the 2008 Conference on Future Play. 2008, p. 228-31.

[12] Anderson EF, Peters CE. On the provision of a comprehensive computer graphics education in the context of computer games: An activity-led instruction approach. In: Domik G, Scateni R, editors. Eurographics 2009 - Education Papers. Eurographics Association; 2009, p. 7-14.

[13] Skillset . Computer games accreditation: Current education report. Available from: http://www.skillset.org/games/accreditation/article_3700_1.asp; 2005.

[14] Eastwood D. Future framework for research assessment and funding. HEFCE circular letter number 06/2007, the Higher Education Funding Council for England; 2007.

[15] 3D World . 3D Training - The Complete Guide, UK and Eire section. 3D World 2007;88.

[16] 3D World . 3D Training Directory, CGI's Ivy League section. 3D World 2007;98:56-7. 
[17] Armour B. A Different Kind of Artist. SIGGRAPH Comput Graph 1997;31(1):23-5.

[18] Ford Morie J. CGI Training for the Entertainment Film Industry. IEEE Computer Graphics and Applications 1998;18(1):30-7.

[19] Orr G, Alley T, Laxer C, Geigel J, Gold S. A knowledge base for the emerging discipline of computer graphics. CGEMS: Computer Graphics Educational Materials Source, The CGEMS Project; 2007.

[20] Domik G, Goetz F. A Breadth-First Approach for Teaching Computer Graphics . In: EG Education Papers. 2006, p. 1-5.

[21] Sung K, Shirley P. A top-down approach to teaching introductory computer graphics. In: SIGGRAPH '03: ACM SIGGRAPH 2003 Educators Program. 2003, p. 1-4.

[22] McCracken C. Issues in computer graphics education. In: ACM SIGGRAPH 2006 Educators Program. 2006.

[23] Comninos P. Mathematical and Computer Programming Techniques for Computer Graphics. Springer-Verlag; 2005.

[24] Turner P. The language of cinema and traditional animation in the 3d computer animation classroom. In: SIGGRAPH '98: ACM SIGGRAPH 98 Conference abstracts and applications. 1998, p. 80-3.

[25] Cameron J. Avatar. Twentieth Century-Fox Film Corporation http://www.imdb.com/title/tt0499549/; 2009.

[26] Abrams J. Star Trek. Paramount Pictures http://www.imdb.com/title/tt0796366/; 2009.

[27] Yates D. Harry Potter and the Half-Blood Prince. Warner Bros. Pictures - http://www.imdb.com/title/tt0417741/; 2009.

[28] McG . Terminator Salvation. The Halcyon Company http://www.imdb.com/title/tt0438488/; 2009.

[29] Ollila M, Kempff J, Ljungman J. Where industry and academia meet: an international perspective. In: SIGGRAPH '98: ACM SIGGRAPH 98 Conference abstracts and applications. 1998. 
[30] Wands B. The role of creativity in computer graphics education. In: SIGGRAPH '02: ACM SIGGRAPH 2002 conference abstracts and applications. 2002, p. 19-.

[31] Flaxman T. The future of computer animation education. In: SIGGRAPH '03: ACM SIGGRAPH 2003 Educators Program. 2003, p. 1-6.

[32] Bourdin JJ, Cunningham S, Fairén M, Hansmann W. Report of the cge 06 computer graphics education workshop. 2006.

[33] Anderson EF, McLoughlin L. Critters in the classroom: a 3d computergame-like tool for teaching programming to computer animation students. In: SIGGRAPH '07: ACM SIGGRAPH 2007 educators program. 2007.

[34] Mateas M. Procedural literacy: educating the new media practitioner. On The Horizon 2005;13(2).

[35] Dijkstra E. On the teaching of programming, i.e. on the teaching of thinking. EWD473; 1975.

[36] Allen E, Bodik R, Bruce K, Fisher K, Freund S, Harper R, et al. Sigplan programming language curriculum workshop: Discussion summaries and recommendations. ACM SIGPLAN Notices 2008;43(11):6-29. 


\begin{tabular}{|c|c|c|c|}
\hline Year & Technical Units & Production Units & Art Units \\
\hline \multirow{3}{*}{1} & $\begin{array}{l}\text { Mathematics for Computer } \\
\text { Graphics } 1 \\
\text { Introduction to Mathematics }\end{array}$ & \multirow{3}{*}{$\begin{array}{c}\text { Computer Animation } 1 \\
\text { Modelling, Animation \& } \\
\text { Rendering Techniques 1 } \\
\text { Scripting } \\
\text { Set Projects (3) }\end{array}$} & \multirow{3}{*}{$\begin{array}{c}\text { Animation Design } 1 \\
\text { Visual Studies 1 } \\
\text { Cinematography 1 } \\
\text { Writing for Animation } \\
\text { Still \& Moving Image 1 } \\
\text { (History of Art, Film \& } \\
\text { Animation) }\end{array}$} \\
\hline & $\begin{array}{c}\text { Computer Programming } 1 \\
\text { Algorithm Design } \\
\text { Programming in C }\end{array}$ & & \\
\hline & $\begin{array}{c}\text { Computer Systems } \\
\text { Introduction to OS \& } \\
\text { Internet } \\
\text { Computer Hardware }\end{array}$ & & \\
\hline \multirow{3}{*}{2} & $\begin{array}{c}\text { Mathematics for Computer } \\
\text { Graphics 2 } \\
\text { CG Fundamentals }\end{array}$ & $\begin{array}{c}\text { Computer Animation } 2 \\
\text { Animation Techniques } \\
\text { Group Project }\end{array}$ & \multirow{3}{*}{$\begin{array}{c}\text { Animation Design } 2 \\
\text { Visual Studies } \\
\text { (Character Design) } \\
\text { Cinematography } 2 \\
\text { Motion Studies } \\
\text { Still \& Moving Image 2 } \\
\text { (History of Animation \& } \\
\text { Computer Animation) }\end{array}$} \\
\hline & $\begin{array}{c}\text { Computer Programming } 2 \\
\text { Software Design \& C++ } \\
\text { OpenGL }\end{array}$ & $\begin{array}{c}\text { Digital Media Applications } \\
\text { \& Postproduction } \\
\text { Techniques }\end{array}$ & \\
\hline & $\begin{array}{l}\text { Operating Systems } \\
\text { Techniques } \\
\text { Linux, Python }\end{array}$ & $\begin{array}{c}\text { Specialist Project } \\
\text { (Animation or Programming) }\end{array}$ & \\
\hline \multirow{3}{*}{3} & $\begin{array}{c}\text { Animation Systems } \\
\text { Techniques } \\
\text { History of CA Techniques } \\
\text { Curve. Surfaces \& Volumes }\end{array}$ & $\begin{array}{c}\text { Computer Animation } 3 \\
\text { Master Classes } \\
\text { Professional Practice }\end{array}$ & \multirow[t]{3}{*}{$\begin{array}{c}\text { Animation Design } 3 \\
\text { Innovations in Computer } \\
\text { Animation } \\
\text { (Project \& Report) }\end{array}$} \\
\hline & $\begin{array}{c}\text { Textures } \\
\text { Particle Systems }\end{array}$ & \multirow{2}{*}{ Major Project \& Report } & \\
\hline & $\begin{array}{c}\text { Computer Programming } 2 \\
\text { Tool Design } \\
\text { C++ Programming }\end{array}$ & & \\
\hline
\end{tabular}

Table 1: Units in our original BA-CVA Programme. 


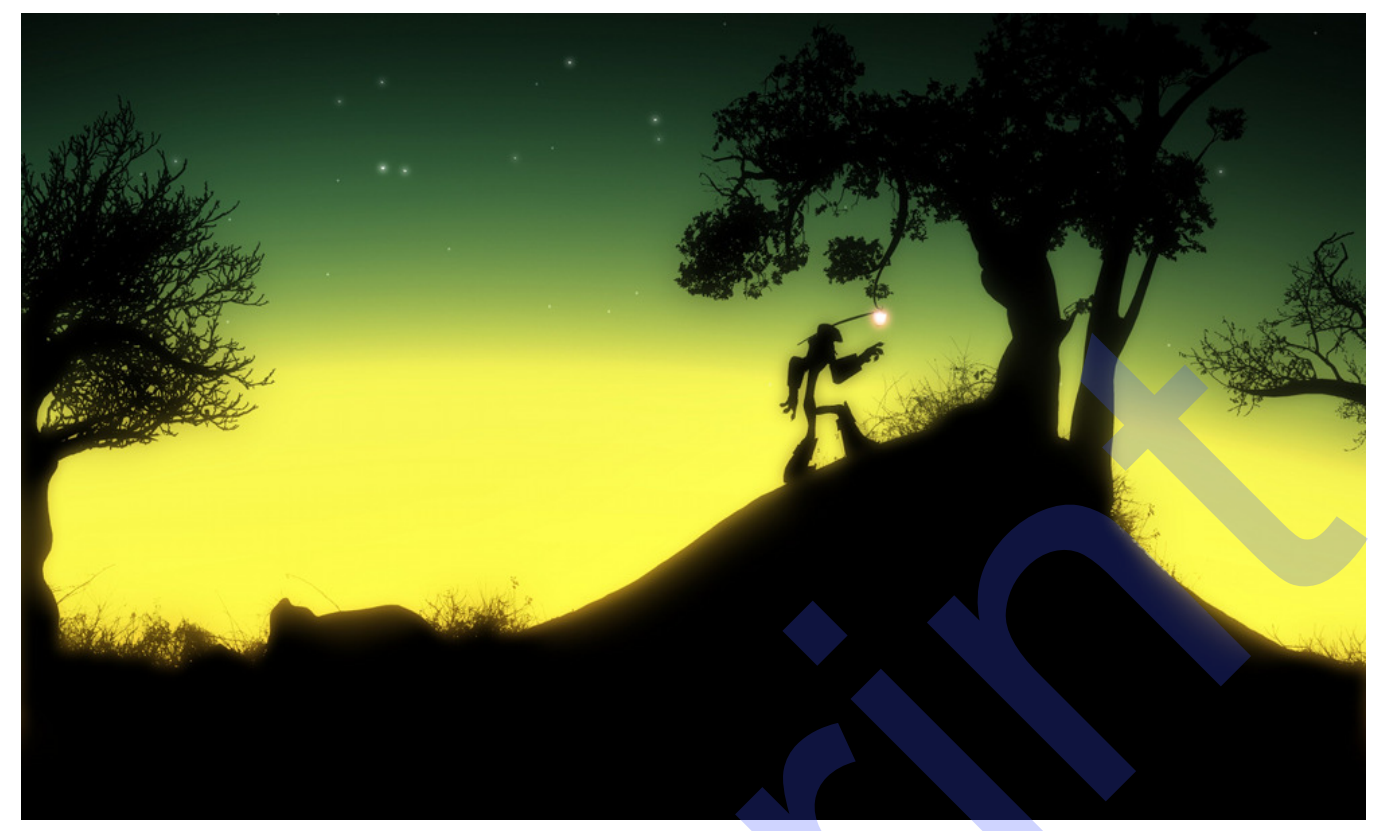

Figure 1: Student project "Harvester" (2008) by Nicholas Hampshire.

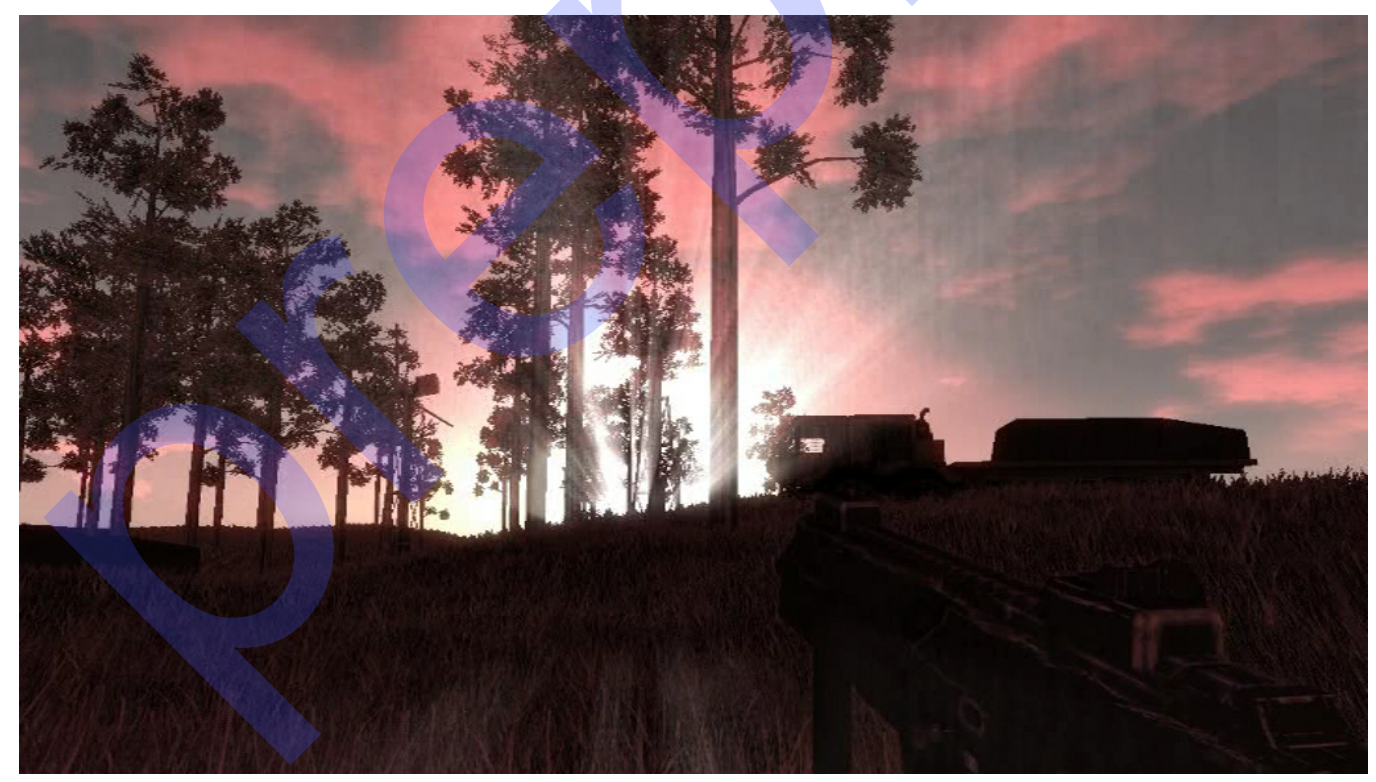

Figure 2: Student project "Black Skies" (2009) by Simon Roth. 


\begin{tabular}{|c|c|c|c|c|c|}
\hline \multirow[t]{2}{*}{ Year } & \multicolumn{2}{|c|}{ Technical Units } & \multirow{2}{*}{$\begin{array}{c}\text { Production Units } \\
3\end{array}$} & \multicolumn{2}{|c|}{ Art Units } \\
\hline & 1 & 2 & & 4 & 5 \\
\hline \multirow{2}{*}{1} & $\begin{array}{l}\text { Mathematical Methods } 1 \text { (20) } \\
\text { Differential and Integral } \\
\text { Calculus, Analytical Geometry, } \\
\text { Trigonometry, Polynomials, } \\
\text { Complex Numbers }\end{array}$ & $\begin{array}{l}\text { Discrete Mathematics (20) } \\
\text { Sets, Number Systems, } \\
\text { Mappings, Function Theory, } \\
\text { Prepositional Logic, Boolean } \\
\text { Algebra, Sequences, Vectors, } \\
\text { Matrices, Proofs }\end{array}$ & \multirow{2}{*}{$\begin{array}{c}\text { Computer Animation } \\
\text { Production 1.1 (20) } \\
\text { \& } \\
\text { Computer Animation } \\
\text { Production 1.2 (20) } \\
\text { Animation Techniques1, } \\
\text { Post-Production Techniques 1, } \\
\text { Group Project 1 }\end{array}$} & \multirow{2}{*}{$\begin{array}{c}\text { Design for Animation 1: } \\
\text { Theory \& Practice (40) } \\
\text { Visual Studies, } \\
\text { Cinematography, } \\
\text { Animation Principles and } \\
\text { Practices, } \\
\text { Critical and Contextual Studies }\end{array}$} & $\begin{array}{l}\text { Mathematics for Computer } \\
\text { Graphics (20) } \\
\text { Introduction to Mathematics }\end{array}$ \\
\hline & $\begin{array}{l}\text { Fundamentals of Computer } \\
\text { Science and Computer } \\
\text { Architecture (20) } \\
\text { Fundamentals of Computer } \\
\text { Science Theme, Introduction to } \\
\text { Operating Systems, Hardware }\end{array}$ & $\begin{array}{l}\text { Principles \& Practice of } \\
\text { Programming (20) } \\
\text { Procedural Programming, } \\
\text { Algorithm Design \& } \\
\text { Implementation, Object } \\
\text { Orientation }\end{array}$ & & & $\begin{array}{l}\text { Computing for Graphics (20) } \\
\text { Algorithm Design, } \\
\text { Programming in C and Python }\end{array}$ \\
\hline \multirow{2}{*}{2} & $\begin{array}{l}\text { Mathematical Methods } 2 \text { (20) } \\
\text { Further Mathematical and } \\
\text { Numerical Methods } \\
\text { AI Techniques for Animation } \\
\text { and Games }\end{array}$ & $\begin{array}{c}\text { Mathematics \& Algorithms } \\
\text { for Computer Graphics (20) } \\
\text { CG Fundamentals, } \\
\text { Lighting \& Rendering } \\
\text { Techniques }\end{array}$ & $\begin{array}{l}\text { Computer Animation } \\
\text { Production 2 (20) } \\
\text { Animation Techniques 2, Post- } \\
\text { Production Techniques 2 } \\
\text { Group Project 2 }\end{array}$ & \multirow{2}{*}{$\begin{array}{l}\text { Design for Animation 2: } \\
\text { Theory \& Practice (40) } \\
\text { Advanced Visual Studies, } \\
\text { Advanced Cinematography, } \\
\text { Advanced Critical and } \\
\text { Contextual Studies, } \\
\text { Visiting Practitioners }\end{array}$} & \multirow{2}{*}{$\begin{array}{c}\text { Aesthetics \& Techniques } 1 \\
\text { (40) } \\
\text { Advanced Animation Principles } \\
\text { and Practice, } \\
\text { Digital Image Techniques, } \\
\text { Professional Practice and } \\
\text { Methods 1 }\end{array}$} \\
\hline & $\begin{array}{l}\text { Principles of Software } \\
\text { Engineering \& Operating } \\
\text { Systems (20) } \\
\text { The Software Engineering. } \\
\text { Languages and Compilers, } \\
\text { OS Techniques }\end{array}$ & $\begin{array}{c}\text { Object Oriented } \\
\text { Programming \& Graphics } \\
\text { (20) } \\
\text { Software Design \& C++ } \\
\text { OpenGL }\end{array}$ & $\begin{array}{l}\text { Specialist Production Project } \\
\text { (20) } \\
\text { (Animation or Programming) }\end{array}$ & & \\
\hline \multirow{3}{*}{3} & \multirow{3}{*}{$\begin{array}{c}\text { Collaborative Research } \\
\text { Project (20) } \\
\text { Project \& Report }\end{array}$} & $\begin{array}{c}\text { Animation \& Games Systems } \\
\text { Techniques (20) } \\
\text { History of CA \& CG } \\
\text { Techniques, Game Engines, }\end{array}$ & $\begin{array}{l}\text { Master Classes in Computer } \\
\text { Graphics Techniques (20) } \\
\text { Industry Set Project \& } \\
\text { Professional Practice }\end{array}$ & \multirow{3}{*}{$\begin{array}{l}\text { Innovations in Computer } \\
\text { Animation (20) } \\
\text { Experimental Project \& Report }\end{array}$} & \multirow{3}{*}{$\begin{array}{c}\text { Aesthetics \& Techniques } 2 \\
\text { (40) } \\
\text { Professional Practices and } \\
\text { Methods } 2, \\
\text { Animation and Aesthetics }\end{array}$} \\
\hline & & Textures,Particle Systems & \multirow[b]{2}{*}{ Major Project \& Report (40) } & & \\
\hline & & $\begin{array}{c}\text { Advanced Graphics Software } \\
\text { Development Techniques (20) } \\
\text { Advanced real-time Graphics } \\
\text { Programming Techniques } \\
\text { API Programming }\end{array}$ & & & \\
\hline
\end{tabular}

Table 2: Units in our new BA / BSc Programme Framework.

Columns 1, 2 \& 3 represent the BSc SDAGE - Columns 2, 3 \& 4 the BA CVA - Columns 3, $4 \& 5$ the BA CAA. 